\title{
Molecular phylogenetic relationships among Lachenalia, Massonia and Polyxena (Liliaceae) on the basis of the internal transcribed spacer (ITS) region
}

\author{
Shuichi Hamatani ${ }^{1,6}$, Yu Masuda ${ }^{2}$, Katsuhiko Kondo ${ }^{2,3}$, \\ Eiichi Kodaira ${ }^{4,5}$ and Hisao Ogawa ${ }^{4}$ \\ ${ }^{1}$ The Hiroshima Botanical Garden, 495 Kurashige 3, Saeki-ku, Hiroshima 731-5156, Japan; \\ ${ }^{2}$ Laboratory of Plant Chromosome and Gene Stock, Graduate School of Science, Hiroshima \\ University, 1-4-3 Kagamiyama, Higashi-Hiroshima 739-8526, Japan; \\ ${ }^{3}$ Laboratory of Plant Genetics and Breeding Science, Faculty of Agriculture, \\ Tokyo University of Agriculture, 1737 Funako, Atsugi 243-0034, Japan; \\ ${ }^{4}$ The Kyoto Botanical Garden, Shimogamo-nakaragi-cho, Sakyo-ku, Kyoto 606-0823, Japan; \\ ${ }^{5}$ Kyoto Herbal Garden, Takeda Pharmaceutical Company Limited, 11, \\ Ichijoji Takenouchi-Cho, Sakyo-Ku, Kyoto 606-8134, Japan \\ ${ }^{6}$ Author for correspondence (hamasyu@ma6.seikyou.ne.jp) \\ Received July 21, 2008; accepted November 30, 2008
}

\begin{abstract}
A molecular phylogenetic analysis based on internal transcribed spacer (ITS) sequences in 31 species, four varieties and four cultivars of Lachenalia, two species of Massonia and three species of Polyxena was made. These three genera have been considered as closely related with each other. The ITS sequence data confirmed that Massonia was clearly different from Lachenalia and Polyxena. Polyxena constructed one clade distinguished from Lachenalia. The species of Lachenalia used showed a correlationship between ITS sequence data and karyotypes, excepting the species with the basic chromosome numbers $x=7$ and $x=8$ did not show any correlationship with those with the other basic chromosome numbers. Similarities of their arrays of ITS sequence data among species with $\mathrm{x}=8$ were greater than those among the species with $\mathrm{x}=7$. Lachenalia pusilla and L. muirii which had $\mathrm{x}=7$ formed a clade with the species with $\mathrm{x}=8$. Differences in The species with the basic chromosome numbers of $\mathrm{X}=7$ and 8 showed less differences in correlationship between ITS sequence data and karyotypes than those with other basic chromosome numbers It was suggested that the species of Lachenalia with the basic chromosome numbers of $\mathrm{x}=7$ and 8 might be originated from a common ancestor, while the other species of the genus with basic chromosome numbers other than $x=7$ and 8 might be originated from other ancestor-else.
\end{abstract}

\section{KEYWORDS: Lachenalia, Massonia, Polyxena, Phylogenetic analysis, ITS, Karyotype}

Lachenalia is an important genus in the Liliaceae, sometimes placed in the Hyacinthaceae. The genus is endemic to the western part of southern Africa and consists of approximately 115 species (Duncan 1998).

Since the genus has subtle, morphological differences in rather small area, it has been classified into numerous species. However, it has been difficult to study phylogenetic relationships, speciation and other species biology. The previous cladistic analyses by Duncan (1988) and Duncan et al. (2005) made in 73 characters included flowers, bulbs and seeds in the members of the genus indicated that all those morphological data could be inadequate to clarify and justify the species relationships. They suggested that molecular comparisons in Lachenalia.

Molecular data in $\operatorname{atp} B$ and $\operatorname{trn} L-F$ chloroplast DNA sequence data were studied in six species in the tribe Massonieae, the family Hyacinthaceae by Pfosser et al. (2003) suggesting Massonia and Polyxena were closely related to Lachenalia.

Chromosome numbers of 61 species and eight varieties in Lachenalia documented showed aneuploid chromosome numbers of $2 \mathrm{n}=10,12,14,16,17,18,21,22,23,24,26$, 27, 28, 29, 30, 32, 40, 42, 44, and 56 (e.g., Gouws 1965, Ornduff and Watters 1978, Nordenstam 1982, Johnson and Brandham 1997, Hamatani et al. 1998, 2004, 2007).
Karyotypes of 35 species and four varieties of the genus were studied and classified into nine groups (Hamatani et al. 1998, 2004, 2007), however, they were not consistent with those of the cladistic analysis of Duncan et al. (2005). More deep studies in their karyotypes deposited problematic with patterns such as intermediate karyotypes among certain groups, triploid-like and natural hybridlike karyotypes, non-uniformity of intraspecific karyotypes. It seemed that morphological and karyomorphological data were not sufficient to construct phylogenetic relationships of the species in Lachenalia.

The present phylogenetic study was conducted in the internal transcribed spacer (ITS) region in nuclear DNA sequences in 31 species, four varieties and four cultivars in Lachenalia, two species of Massonia and three species of Polyxena.

\section{Materials And Methods}

Plant materials The plants used in this study were tabulated in Table 1. They were cultivated in the Hiroshima Botanical Garden and Kyoto Botanical Garden. Ornithogalum, the Scilloideae, the Liliaceae was used as the outgroup in this study.

DNA isolation, PCR and Sequencing Total DNA of each species studied was extracted from fresh leaves using the 


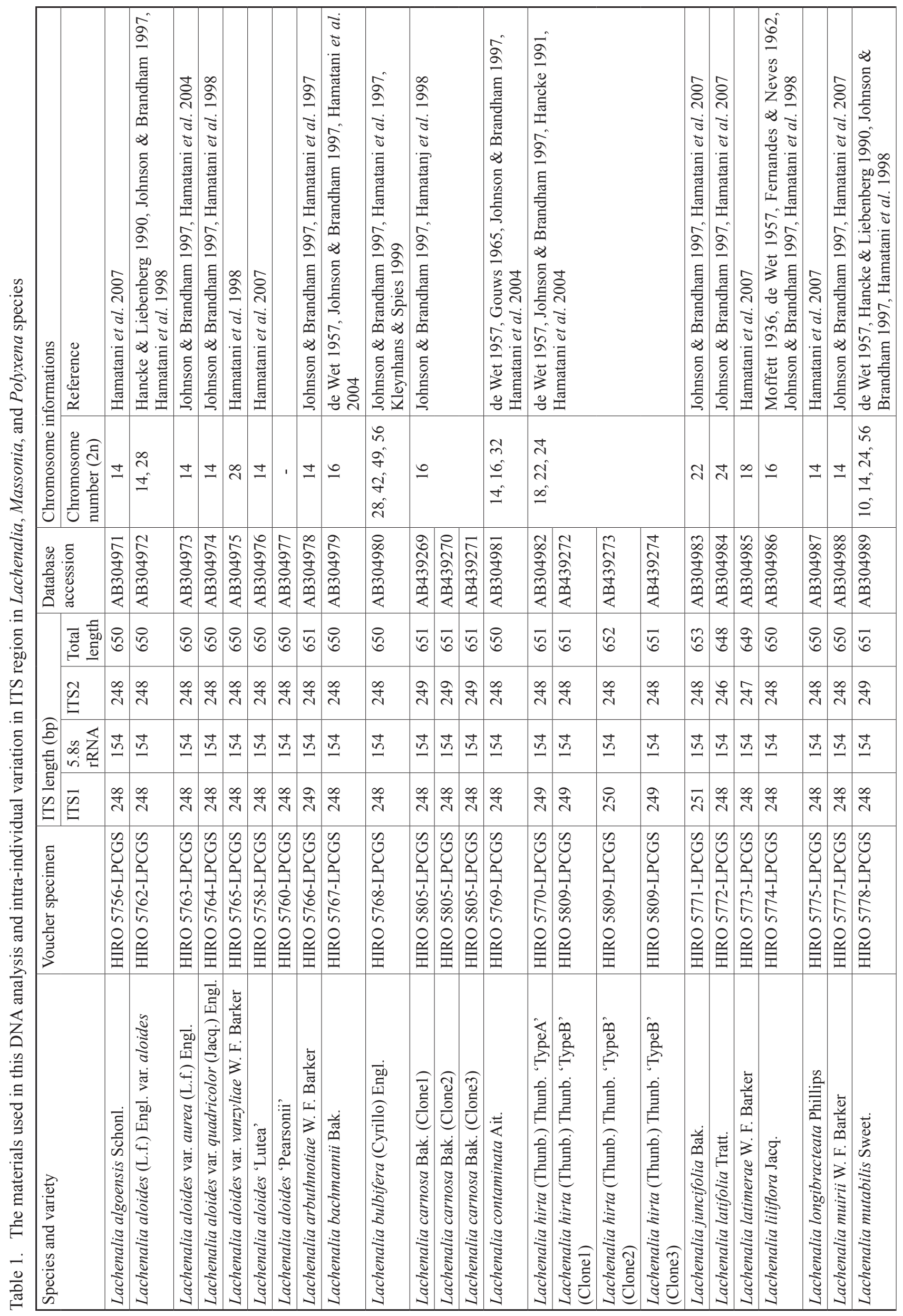




\begin{tabular}{|c|c|c|c|c|c|c|c|c|c|c|c|c|c|c|c|c|c|c|c|c|c|c|c|c|c|c|c|c|}
\hline 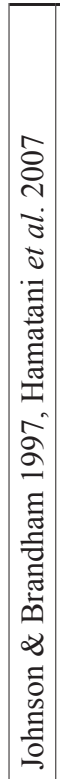 & 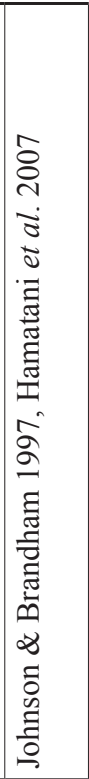 & 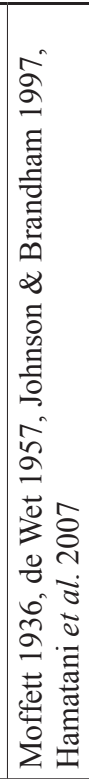 & 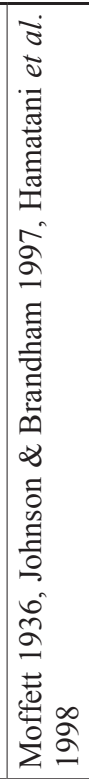 & 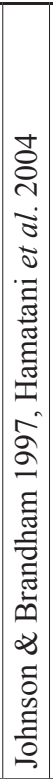 & 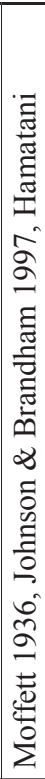 & 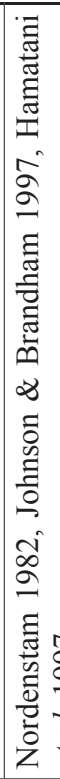 & & 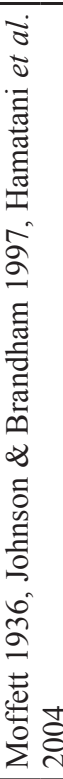 & & 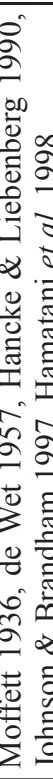 & & & & 0 & 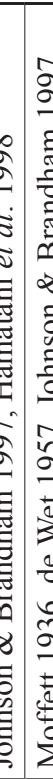 & 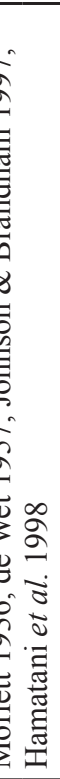 & & & & 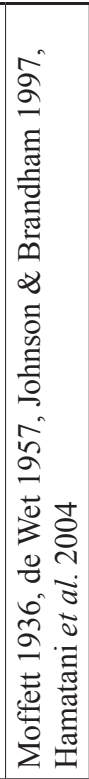 & 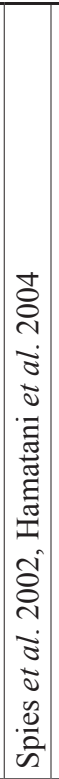 & 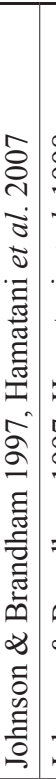 & 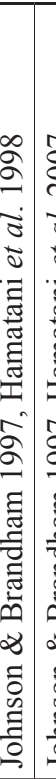 & 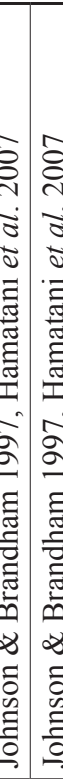 & 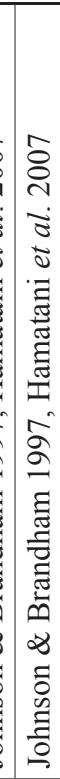 & 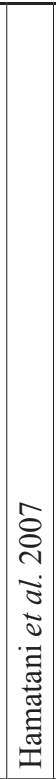 & 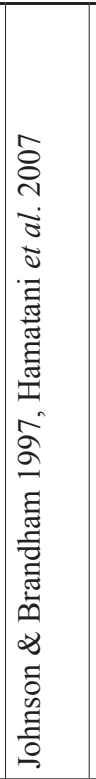 & \\
\hline 0 & $\underset{\sim}{\infty}$ & 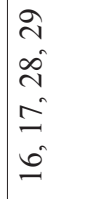 & 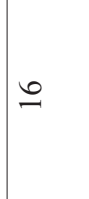 & $\begin{array}{l} \pm \\
I \\
I\end{array}$ & $\because$ & $\begin{array}{l}\stackrel{0}{ } \\
\pm\end{array}$ & & $\stackrel{0}{0}$ & & f & & & & & 0 & & & & & 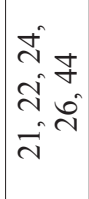 & & $\Xi$ & & & 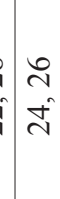 & $\underset{\sim}{\infty}$ & $\begin{array}{l}\stackrel{0}{1} \\
i \\
d\end{array}$ & \\
\hline & 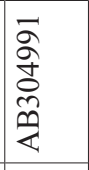 & 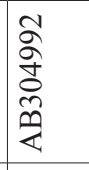 & 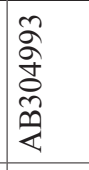 & 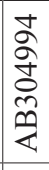 & 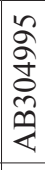 & 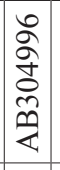 & $\begin{array}{l}\hat{a} \\
\dot{a} \\
\dot{0} \\
\hat{n} \\
\dot{z}\end{array}$ & 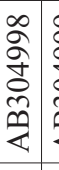 & & 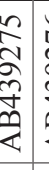 & & 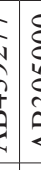 & & & $\begin{array}{l}5 \\
b \\
5\end{array}$ & 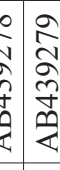 & $\begin{array}{l}\mathscr{D} \\
\widetilde{N} \\
\tilde{m}\end{array}$ & 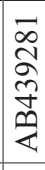 & 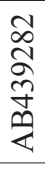 & 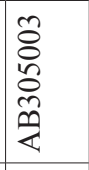 & 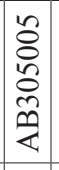 & 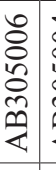 & 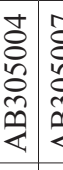 & 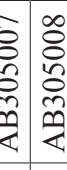 & $\begin{array}{l}0 \\
0 \\
0 \\
2 \\
0 \\
\tilde{n} \\
\frac{n}{4}\end{array}$ & 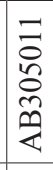 & 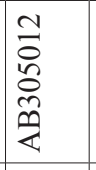 & 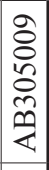 \\
\hline 2 & 8 & in & in & in & $\sqrt{6}$ & ơ & f & $\sqrt{6}$ & $\sqrt{6}$ & 8 & $?$ & $b$ & $?$ & & $\overrightarrow{6}$ & 6 & gै & है & 8 & है & 8 & ถి & हై & 6 & $\sqrt{6}$ & $\overrightarrow{8}$ & f & f \\
\hline$\stackrel{+}{\sim}$ & $\stackrel{\infty}{\sim}$ & $\stackrel{\infty}{\sim}$ & $\underset{+}{\infty}$ & $\stackrel{\infty}{\sim}$ & $\stackrel{\text { I }}{\sim}$ & $\stackrel{\mathscr{q}}{\sim}$ & 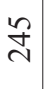 & $\underset{\sim}{\sim}$ & f & $\stackrel{\infty}{\sim}$ & o & 宽 & $p$ & & 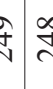 & 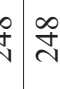 & $\stackrel{\infty}{\sim}$ & $\stackrel{\infty}{\sim}$ & $\stackrel{\infty}{\sim}$ & $\stackrel{\infty}{\sim}$ & $\stackrel{\infty}{\sim}$ & $\stackrel{\infty}{\sim}$ & 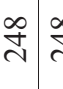 & $\stackrel{\infty}{\stackrel{\infty}{N}} \stackrel{\infty}{\sim}$ & $\stackrel{\text { I }}{\text { I }}$ & 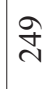 & $\stackrel{0}{\sim}$ & $\tilde{N}$ \\
\hline$\stackrel{t}{\Delta}$ & $\stackrel{+}{\stackrel{t}{2}}$ & 总 & 点 & 点 & 芯 & $\stackrel{g}{I}$ & $\stackrel{\Delta}{=}$ & $\stackrel{t}{\rightarrow}$ & $f_{0}$ & $\stackrel{\Delta}{\Delta}$ & $\dagger$ & 5 & 5 & t. & 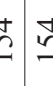 & t & $\stackrel{ \pm}{n}$ & $\stackrel{\stackrel{H}{2}}{ }$ & $\stackrel{+}{n}$ & 总 & $\stackrel{\Delta}{\varrho}$ & 点: & $\stackrel{\Delta}{2}$ & 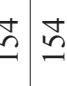 & $\stackrel{\stackrel{b}{n}}{ }$ & $\stackrel{+}{\stackrel{2}{2}}$ & 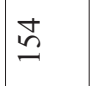 & 乞 \\
\hline f & $\stackrel{\infty}{\sim}$ & $\stackrel{\infty}{\sim}$ & $\stackrel{\infty}{\sim}$ & $\stackrel{\infty}{\stackrel{\infty}{\sim}}$ & $\stackrel{\infty}{\stackrel{\infty}{\sim}}$ & $\stackrel{\infty}{\stackrel{\infty}{\sim}}$ & $\stackrel{\infty}{\sim}$ & 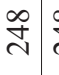 & t & $\stackrel{\substack{\infty \\
\sim}}{\sim}$ & 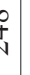 & fo & s & t & 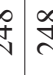 & 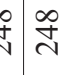 & 守 & $\stackrel{\infty}{\sim}$ & $\stackrel{\infty}{\sim}$ & $\stackrel{2}{n}$ & $\stackrel{\infty}{\sim}$ & $\stackrel{\infty}{\sim}$ & $\overrightarrow{\vec{n}}$ & 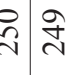 & $\underset{\sim}{\stackrel{g}{v}}$ & $\stackrel{\infty}{\sim}$ & 守 & $\stackrel{2}{2}$ \\
\hline 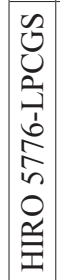 & 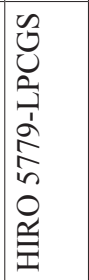 & 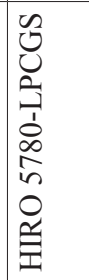 & 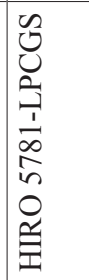 & 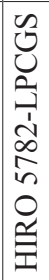 & 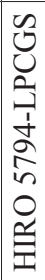 & 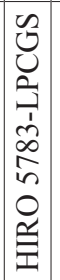 & 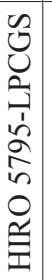 & 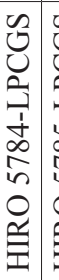 & & 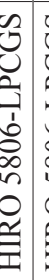 & & $\begin{array}{l}b \\
b \\
b \\
b \\
b\end{array}$ & & 6 & 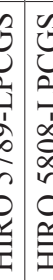 & 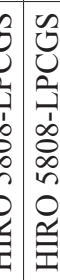 & 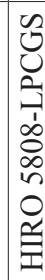 & 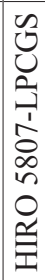 & $\begin{array}{l}0 \\
0 \\
0 \\
0 \\
0 \\
0 \\
0 \\
0 \\
0 \\
0 \\
1 \\
\mid\end{array}$ & 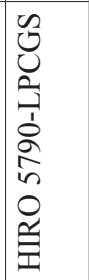 & 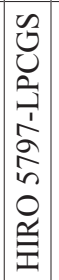 & 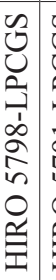 & 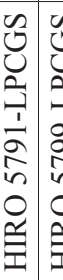 & 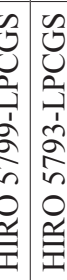 & 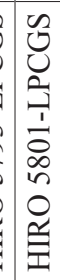 & 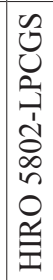 & 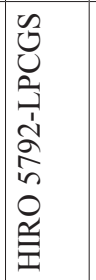 & $\mid \begin{array}{c}0 \\
0 \\
0 \\
1 \\
\hat{0} \\
0 \\
n \\
0 \\
2 \\
\end{array}$ \\
\hline 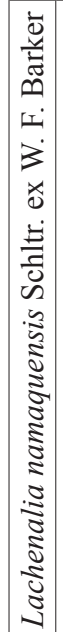 & 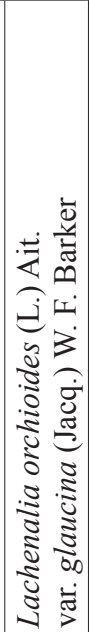 & 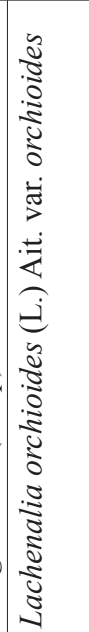 & 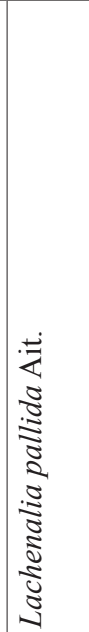 & 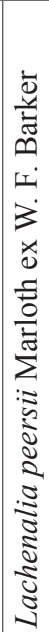 & 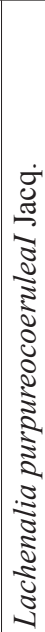 & 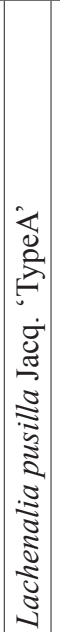 & 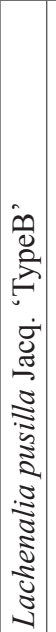 & 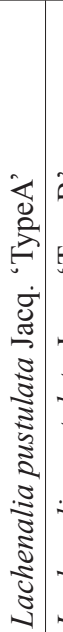 & & 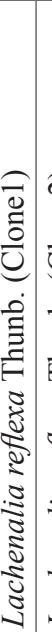 & & 5 & & & 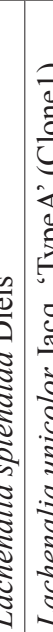 & 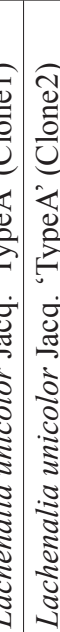 & 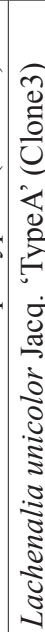 & 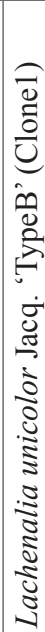 & 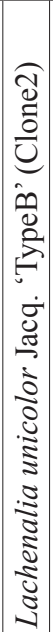 & 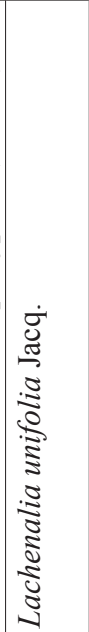 & 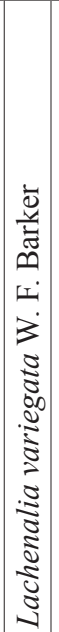 & |. & 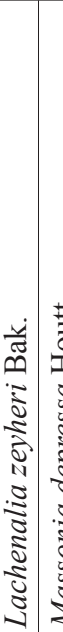 & 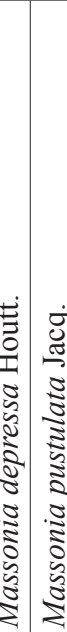 & 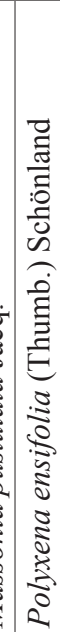 & 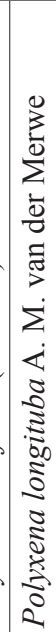 & 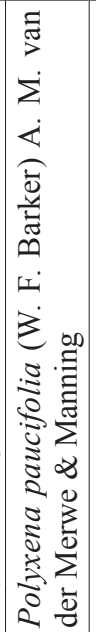 & 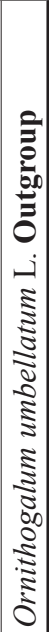 \\
\hline
\end{tabular}


CTAB method (Doyle and Doyle 1987). The nucleotide sequences of ITS $1,5.8 \mathrm{~S}$, and ITS 2 were amplified from the total DNA using ITS 5 (5'-GGAAGTAAAAGTCG TAACAAGG-3') and ITS 4 (5'-TCCTCCGCTTATTG ATATGC-3') PCR primers (White et al. 1990). The PCR amplifications were performed using a GeneAmp PCR system 2700 (Perkin-Elmer, Boston, Massachusetts, U.S.A.) with a thermal cycler program for an initial 1 min denaturation at $97^{\circ} \mathrm{C}$, and then, 27 cycles at $97^{\circ} \mathrm{C}$ for $1 \mathrm{~min}$, at $52^{\circ} \mathrm{C}$ for $1 \mathrm{~min}$, and at $72^{\circ} \mathrm{C}$ for $2 \mathrm{~min}$, followed by an extension step at $72^{\circ} \mathrm{C}$ for $7 \mathrm{~min}$.

The ITS PCR products were subjected to agarose gel (1\%) electrophoresis. The ITS PCR products were subjected to agarose gel (1\%) electrophoresis. The resulting PCR products were, then, purified with the QIA quick gel extraction kit (Qiagen, Calif., U.S.A.). The ITS regions were sequenced with an automated sequencer (3130x Genetic Analyzer; ABI Prism, Foster City, CA, USA) using the Big Dye Terminator Kit (ABI) according to the manufacturer's protocol.

Some of PCR products such as Lachenalia carnosa, $L$. hirta cv. 'Type B,' L. reflexa and L. unicolor 'Type A' and 'TypeB' which showed difficulty in obtaining clean sequences from direct PCR sequencing were cloned using pGEM-T Easy Vector Systems (Promega, Madison, WI, USA) following the manufacture's protocol. Escherichia coli strain JM109 (TaKaRa Bio, Otsu, Japan) were used for transformation. Then blue/white selection was performed and plasmid DNA were extraced using Wizard miniprep (Promega, Madison, WI, U.S.A.).

Data analysis The sequences obtained were aligned using the Clustal W program (Thompson et al. 1994) on the DNA Data Bank of Japan (DDBJ) website (http:// www.ddbj.nig.ac.jp) with the default settings followed by adjustment by eye. The phylogenetic tree was constructed with two program packages such as (1) PAUP 4.0b (Swofford 2000) for the maximum parsimony (MP) method (Fitch 1971) with a heuristic search of 1,000 random addition replicates performed by tree bisectionreconnection (TBR) and MulTree and (2) MrBayes 3.1.2 (Ronquist and Huelsenbeck 2003) with the Bayesian inference (BI) method using the GTR $+\mathrm{G}$ model with $50,000,000$ generations, prior to phylogenetic reconstruction; MrModeltest 2.2 (Nylander 2004) was implemented in hierarchical likelihood ratio tests to allow us to make a rational decision regarding the nucleotide-based substitution model that the best fitted data used for the BI method. The bootstrap (BS) analyses with the MP method was conducted on 1,000 replicates using the heuristic search option in PAUP (Felsenstein 1985), and the Bayesian posterior probabilities (PPB) were calculated using MrBayes. Each of the two methods were executed on data without indels.

\section{Results}

Nucleotide sequence analysis and comparison. The data matrix of ITS included 659 base pairs (bp). Amplification of the ITS regions using the primer pair described above gave PCR products of approximately $650 \mathrm{bp}$ (647-653) in length, except $640 \mathrm{bp}$ in L. pusilla 'Type A'and 644 bp in $O$. umbellatum (outgroup). The nucleotide sequence data reported in this paper will appear in the DDBJ, EMBL, and GenBank databases under accession numbers AB304971 to AB305012 and AB439269 to AB439282. Then, the boundaries of ITS 1 and ITS 2 and the nuclear rDNA coding regions were determined by comparing them with a sequence of $18 \mathrm{~S}-26 \mathrm{~S}$ nrDNA cistron of Tulipa clusiana (Liliaceae) (Accession No. AM180460). The length of the amplified ITS regions is as follows: the length of ITS 1 varied from 246 to $251 \mathrm{bp}$ (except $263 \mathrm{bp}$ in O. umbellatum), the length of the 5.8S rRNA was 154 bp (except $149 \mathrm{bp}$ in L. pusilla 'TypeA'), and the length for ITS 2 varied from 243 to $249 \mathrm{bp}$ (except $227 \mathrm{bp}$ in $O$. umbellatum) (Table 1).

Phylogenetic analysis. Total number of rearrangements tried in MP analysis of the ITS data was 49,706,079 and score of best trees found was 351 , with a consistency index, including uninformative characters (CI), of 0.809 and a retention index (RI) of 0.856 for the data without indels. A total of 135 distinct data patterns under the bestfit model indicated the GTR $+\mathrm{G}$ substitution model by MrModeltest for the dataset.

All the analyses and supporting values for each method are shown in Fig. 1. BP indicates BS values as percentages based on 1,000 replications using the MP method, and PPB indicates Bayesian posterior probabilities as percentages.

In the consensus tree based on the ITS sequences, two species of Massonia was made one clade and distinguished from the clade constructed by Lachenalia and Polyxena $(\mathrm{BS}=100 \%, \mathrm{BPP}=1.00)$ (Fig. 1).

In the clade constructed by Lachenalia and Polyxena (99.9\%, 0.99), two clades were made with high values; one was Clade I $(90.0 \%, 1.00)$ made from three species of Polyxena and another was Clade II $(976 \%, 1.00)$ made from Lachenalia unifolia, L. juncifolia and L. zeyheri, and one clade (Clade III) with low values $(68.8 \%, 0.89)$ made from 25 species, four varieties and five cultivers (41 samples) which were from L. bachmannii to L. rosea. Four samples of $L$. hirta made one clade $(99.4 \%, 1.00)$ from one species, and L. latimerae and L. latifolia were not included in clades.

In Clade III included one major clade (Clade IV; $83.3 \%, 1.00)$ consisting of twelve species and three cultivars from L. bachmannii to L. pusilla, and included other 13 species, four varieties and two cultivars ("Others"). In Clade IV, eleven species and two cultivars (except for L. pusilla) made smaller clade 78.0\%, 1.00). In this smaller clade, moreover L. unicolor and L. pallida made smaller clade $(90.9 \%, 1.00)$, and other taxa did not 

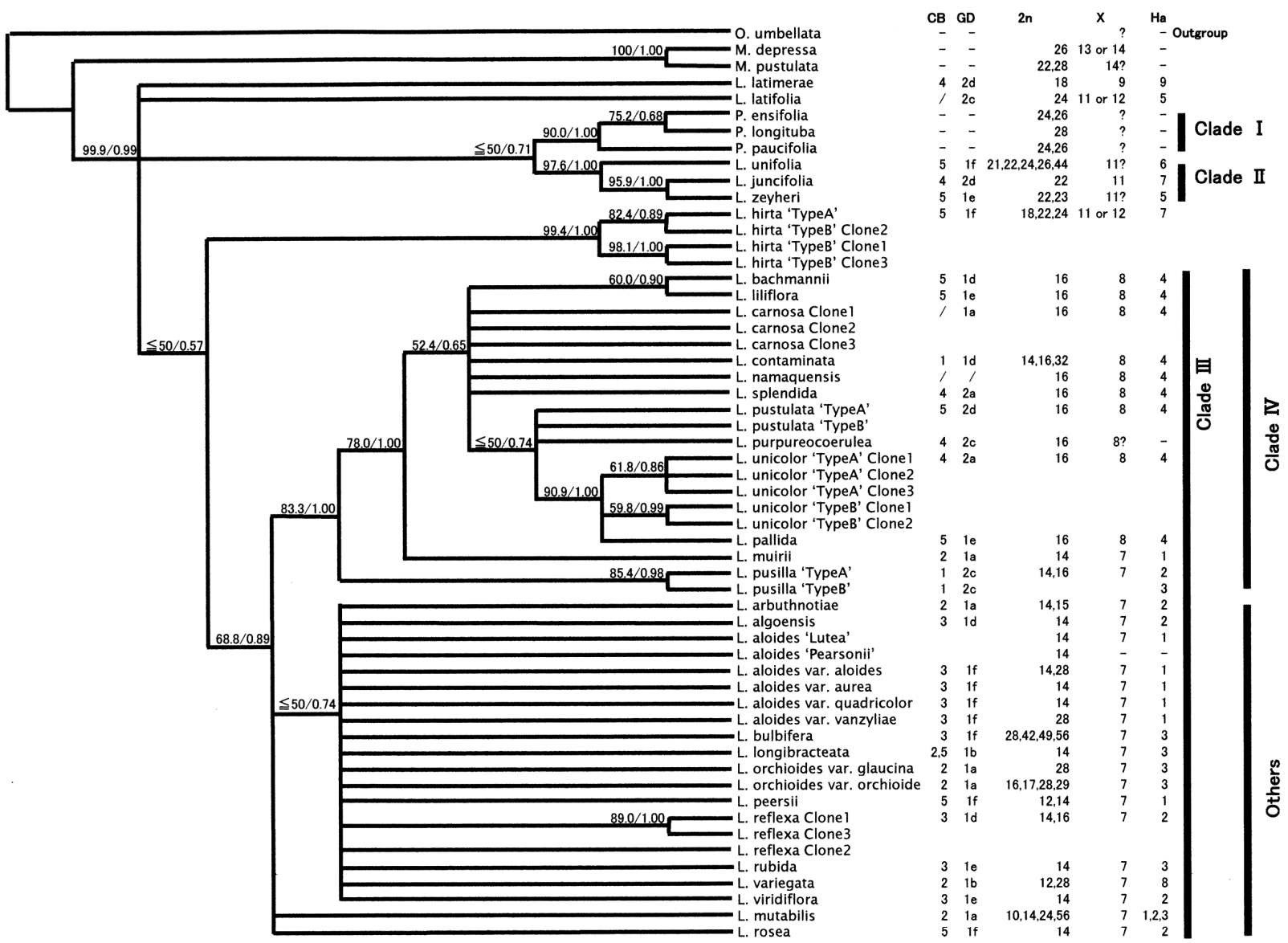

Fig. 1. The strict consensus tree based on the internal transcribed spacer (ITS) sequence data without indels. Numbers listed along the branch show bootstrap values based on 1,000 replications using MP method by PAUP (BP), and Bayesian posterior probabilities by MrBayes (PPB) (BP in \% / PPB). Supporting values more than 50\% were overlaid (less than $50 \%$, but with the most support in each method, were indicated as $\leqq 50$ ).

Data of "CB" show classifications referred from Manning et al. (2002). Data of "GD" show classifications referred from Duncan (1988). Data of " $2 n$ " are their chromosome numbers referred from previous reports. Data of " $\mathrm{x}$ " are their basic chromosome numbers and "Ha" show classifications both referred from Hamatani et al. (1998, 2004 and 2007).

made clear clades.

\section{Discussion}

Lachenalia, Massonia, and Polyxena in the Liliaceae are considered to be closely related to each other (Manning et al. 2002, Pfosser et al. 2003). Based on the results in the ITS, Massonia was clearly distinguished from Lachenalia and Polyxena by forming a clade separate from that of Lachenalia and Polyxena. This result agrees with the analysis of atpB and trnL-F by Pfosser et al. (2003) and with the comparison of karyotypes by Hamatani et al. (2007).

The morphological differences between Polyxena and Lachenalia are very clear (Manning et al. 2002). In the study of karyotypes (Hamatani et al. 2007), differences in particular characteristics were observed; for example, the existence of three large chromosomes; and hence, this study supported the results of karyomorphological studies. Alternatively, Manning et al. (2004) suggested that five known species of Polyxena should be incorporated into the genus Lachenalia, according to their $\operatorname{trn} L-F$ and $r b c L$ sequences. In this study comparing ITS regions, it was confirmed that the Polyxena species had elements that distinguished it from the Lachenalia species. The three species of Polyxena, observed in this study, formed one clade (Clade I; $90.0 \%, 1.00$ ) that was separate from the clade formed by the Lachenalia species.

Two methods, based on morphological information, were used to classify the Lachenalia species; one, based on the flower forms, was advocated by Duncan (1988) and the other, based on general plant forms, was advocated by Manning et al. (2002). In this study, we compared the phylogenetic tree constructed from ITS data with the morphological classifications; however, we could not identify particular mutual points (Fig. 1). These two classification methods were useful for horticultural purposes and general identification of plants, but they did not reflect the genetic similarities.

In the 31 species, four varieties and six cultivars of Lachenalia studied, L. unifolia, L. juncifolia, and L. zeyheri formed Clade II, supported by high values $(97.6 \%, 1.00)$. The chromosome numbers of these three 
species were reported to be $2 \mathrm{n}=16,21-24,26$, and 44 , respectively (Moffett 1936, de Wet 1957, Johnson and Brandham 1997, Hamatani et al. 1998, 2004, 2007), and the basic chromosome numbers were considered to be $\mathrm{x}=11$ or 12 . However, L. latifolia and L. hirta $(\mathrm{x}=11$ or 12) (Johnson and Brandham 1997, Hamatani et al. 2004, 2007) did not form a clade with other species. They differed in the comparison of chromosomes and ITS regions.

The 25 species, four varieties and five cultivars of Lachenalia (from L. bachmannii to L. rosea) formed Clade III, supported by low values $(68.8 \%, 0.89)$. The chromosome numbers of species included in this clade were reported as $2 \mathrm{n}=10,12,14-18,21,24,28,32,42$, and 56 (Moffett 1936, de Wet 1957, Gouws 1965, Nordenstam 1982, Hancke 1991, Johnson and Brandham 1997, Kleynhans and Spies 1998, Hamatani et al. 1998, 2004, 2007, Spies et al. 2002), their basic chromosome numbers being $\mathrm{x}=7$ and 8 . Thus, it was considered that the relationship between species with $\mathrm{x}=7$ and 8 were stronger than the relationship between species with $\mathrm{x}=7$ or 8 and $x \neq 7$ and 8 .

Lachenalia. latimerae $(2 \mathrm{n}=18 ; \mathrm{x}=9)$ had a unique chromosome number and did not show strong relationships with any other species in the comparison of ITS data. It did not show notable morphological differences from the Lachenalia species (Duncan 1988, Duncan et al. 2005, Manning et al. 2002); however, in the eastern region, it was one of the most widely distributed species of Lachenalia (Fig. 2).

The species forming Clade III had a basic chromosome number of $\mathrm{x}=7$ or 8 . Twelve species and three cultivars (from L. bachmannii to L. pusilla) formed Clade IV; among these, L. pusilla and L. muirii had a basic chromosome number of $\mathrm{x}=7$, whereas the other ten species and three cultivars had a basic chromosome number of $x=8$. In species forming Clade IV, the relationship between the $\mathrm{x}=8$ species was stronger than the relationship between the $\mathrm{x}=8$ and $\mathrm{x}=7$ species. Furthermore, karyomorphological studies by Hamatani et
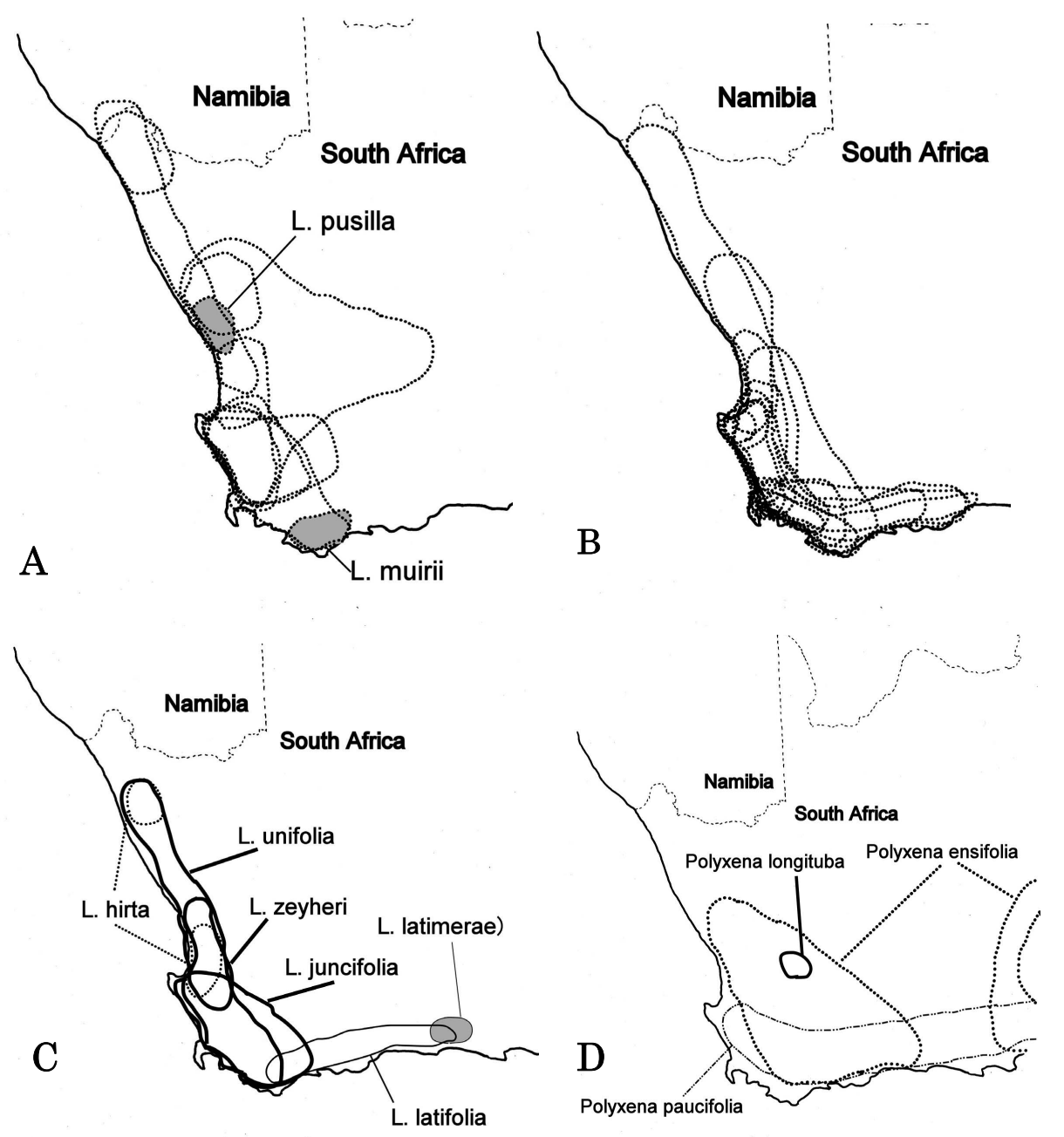

Fig. 2. Habitats of Lachenalia and Polyxena studied.

A: Habitats of species of Clade IV in figure 1. B: Habitats of species of "Others" in figure 1.

$\mathrm{C}$ : Habitats of Lachenalia species which have basic chromosome numbers not as $\mathrm{x}=7$ or 8 .

D: Habitats of species of Polyxena.

Data were referred from website "African Flowering Plants Database". 
al. $(1997,2004,2007)$ reported that the variation of karyotypes between the $\mathrm{x}=8$ species was not as advanced as the variation in the $x=7$ species, because the $x=8$ species showed only one karyotype pattern as compared to four karyotype patterns shown by the $\mathrm{x}=7$ species.

The 13 species, four varieties and two cultivars in Clade III called as "Others" in Fig. 1 (from L. arbuthnotiae to L. rosea), which were not included in Clade IV, did not construct any clades. In the group "Others", it could not discover the relationships among the each species.

Clade IV had high confidence values $(83.3 \%, 1.00)$ and consisted of all species with $\mathrm{x}=8$ and two species with $\mathrm{x}=7$ (L. pusilla and L. muirii). Based on ITS sequence data, these two $\mathrm{x}=7$ species could be clearly distinguished from the other $\mathrm{x}=7$ species ("Others" in Fig. 1), that is 13 species, four varieties and two cultivars. Although, some varieties and cultivars had their elementary species included in "Others", there were no notable combinations that gave close relationships on comparing ITS sequence data. The results did not support the grouping suggested by Hamatani et al. (1997, 2003, 2007) in karyomorphological studies.

Each species in Clade IV and those included in the group "Others" are distributed in a long and narrow area in the south-western part of southern Africa; the distribution of many species and varieties overlapped (Fig. 2). According to Duncan (1988), Lachenalia could hybridize easily. Thus, it was suggested that the speciation of the $\mathrm{x}=7$ and 8 Lachenalia species resulted not only from mutation, but also from hybridizations between species with the same distribution. There are many reports discussing polyploidy and aneuploidy (for example, Hancke and Liebenberg 1990, Hancke 1991, Johnson and Brandham 2007) among the $x=7$ species. Hamatani et al. (2007) showed several variations in the patterns of karyotypes among the $\mathrm{x}=7$ species; however, polyploidy and aneuploidy were reported in only one $(L$. contaminata) $\mathrm{x}=8$ species (Gouws 1965, Johnson and Brandham 1997, Hamatani et al. 2004). There were no variations in the karyotype patterns of $x=8$ species (Hamatani et al. 2007). It was suggested that the $\mathrm{x}=7$ species, speciated from the mutual ancestral species of Clade IV and the "Others" group, expanded their distribution areas through speciation. These new species then independently expanded their distribution areas through further speciation; for example, L. pusilla, $L$. muirii, and the $\mathrm{x}=8$ species studied. Hereafter, the speciation of $\mathrm{x}=7$ and $\mathrm{x}=8$ species may be clarified by research, using L. pusilla, L. muirii, and so forth.

Alternatively, the Lachenalia species with the basic chromosome numbers of $\mathrm{x}=9$ and $\mathrm{x}=11$ or $12(\mathrm{x} \neq 7$ and 8$)$, showed strong relationships between their ITS data, but did not show the general unity exhibited by the $x=7$ and 8 species. Moreover, the $x \neq 7$ and 8 species were considered to have speciated from multiple ancestors since they were not included in the clade formed by the $\mathrm{x}=7$ and 8 species (Clade III). This implies that the ancestors of $x \neq 7$ and 8 and those of $x=7$ and 8 speciated from mutual ancestral species of Lachnelia. According to Johnson and Brandham (1997), these species were the ones with basic chromosome numbers $\mathrm{x}=5,6,10,13$, and 15 , and except for the chromosome numbers considered in this study, the histories of these species will be clarified future studies.

ACKNOWLEDGEMENTS. We would like to thank Mr. Takeshi Koyama for his donation of Lachenalia plants and Mr. Graham Duncan, Specialist Horticulturist of Bulbous Plants, Kirstenbosch Botanical Gardens, for his help in the identification of Lachenalia and Massonia.

\section{Literature Cited}

Doyle, J. J. and Doyle, J. L. 1987. A rapid DNA isolation procedure for small quantities of fresh leaf tissue. Phytochem. Bull. 19: 11-15.

Duncan, G. D. 1988. The Lachenalia handbook. In: J. N. Eloff, Ed., Ann. Kirstenbosch Bot. Gard. 17: 1-69.

Duncan, G. D. 1998. Notes on the genus Lachenalia. Herbertia 53: 40-48.

Duncan, G. D., Edwards, T. J. and Mitchell, A. 2005. Character variation and a cladistic analysis of the genus Lachenalia Jacq.f.ex Murray (Hyacinthaceae). Act. Hort. 673: 113120.

Felsenstein, J. 1985. Confidence limits on phylogenies: an approach using the bootstrap. Evolution 6: 227-242.

Fitch. W. M. 1971. Toward defining the course of evolution: minimum change for a specific tree topology. Syst. Zool. 20: 406-416.

Gouws, J. B. 1964. Cytological studies in the genus Lachenalia Jacq. Ann. Univ. W. Cape 2: 1-7.

Hamatani, S., K. Hasimoto, and K. Kondo. 1998. A comparison of somatic chromosomes at metaphase in Lachenalia (Liliaceae). Chrom. Sci. 2: 21-25.

Hamatani, S., G. Ishida, K. Hashimoto, and K. Kondo. 2004. A chromosome study in ten species of Lachenalia (Liliaceae). Chrom. Sci. 8: 55-61.

Hamatani, S., K. Kondo, E. Kodaira, and H. Ogawa. 2007. Chromosome morphology of 12 species and one variety of Lachenalia and five species of closely related, allied genera (Liliaceae). Chrom. Bot. 2: 79-86

Hancke, F. L. and Liebenberg, H. 1990. B-chromosomes in some Lachenalia species and hybrids. S. Afr. Journ. Bot. 56: 659-664.

Johnson, M. A. T. and P. E. Brandham. 1997. New chromosome numbers in petaloid monocotyledons and in other miscellaneous angiosperms. Kew Bull. 52: 121-138.

Kleynhans, R. and Spies, J. J. 1999. Chromosome number and morphological variation in Lachenalia bulbifera (Hyacinthaceae). S. Afr. Journ. Bot. 65: 357-360.

Moffett, A. A. 1936. The cytology of Lachenalia. Cytologia 7: 490-498.

Manning, J., Goldblatt, P. and Snijman, D. 2002. The color encyclopedia of Cape bulbs. Timber Press, Portland • Cambridge.

Manning, J. C., Goldblatt, P. and Fay, M. F. 2004. A revised generic synopsis of Hyacinthaceae in sub-Saharan Africa, based on molecular evidence, including new combinations and the new tribe Pseudoprosperae. Edinburg Journ. Bot. 60: 533-568.

Nordenstam, B. 1982. Chromosome numbers of southern African plants: 2. Journ. S. Afr. Bot. 48: 273-275.

Nylander, J. A. A. 2004. MrModeltest 2.2. Evolutionary Biology Centre, Uppsala.

Ornduff, R. and P. J. Watters. 1978. Chromosome numbers in 
Lachenalia (Liliaceae). Journ. S. Afr. Bot. 48: 273-275.

Pfosser, M., W. Wetschnig, S. Ungar, and Prenner, G. 2003. Phylogenetic relationships among genera of Massonieae (Hyacinthaceae) inferred from plastid DNA and seed morphology. Journ. Plt. Res. 116: 115-132.

Ronquist, F. and Huelsenbeck, J. P. 2003. MrBayes 3: Bayesian phylogenetic inference under mixed models. Bioiformatics 19(12): 1572-1574.

Spies, J J., van Rooyen, P. and Kleynhans, R. 2002. The Subgeneric Delimitation of Lachenalia (Hyacinthaceae). Acta Hort. 570: 2002.

Swofford, D. L. 2000. PAUP*. Phylogenetic Analysis Using Parsimony (*and Other Methods). Version 4. Sinauer Associates, Sunderland, Massachusetts.
Thompson, J. D., D. G. Higgins, and T. J. Gibson. 1994. CLUSTAL W: improving the sensitity of progressive multiple alignment through sequence weighting, position specific gap penalties and weight matrix choice. Nucl. Acid Res. 22: 4673-4680.

de Wet. J. M. J. 1957. Chromosome numbers in the Scilleae. Cytologia 22: 145-159.

White, T. J., T. Bruns, S. Lee, and J. Tayler. 1990. Amplification and direct sequencing of fungal ribosomal RNA genes for phylogenetics. In PCR protocols: A guide to method and applications. In: M. A. Innis, D. H. Gelfand, J. J. Sninsky and T. J. White, Eds., pp.315-322. Academic Press, San Diego, Calif. 